\title{
Responses to oral methionine supplementation in sheep fed on kale (Brassica oleracea) diets containing S-methyl-L-cysteine sulphoxide
}

\author{
BY T. N. BARRY* AND T. R. MANLEY \\ Invermay Agricultural Research Centre, Private Bag, Mosgiel, New Zealand
}

(Received 17 January 1985 - Accepted 11 July 1985)

1. Responses to twice-weekly oral supplementation with $4.0 \mathrm{~g}$ methionine were measured with lambs $(27 \mathrm{~kg})$ grazing kale (Brassica oleracea) for 10 weeks (Expt 1). In a second experiment with sheep fed on kale at hourly intervals, rumen fractional outflow rates of CrEDTA and ruthenium Tris(1,10 phenanthroline) markers were measured from the rates of decline in their concentrations. Rumen turnover of S-methyl-L-cysteine sulphoxide (SMCO) and of carbohydrate (CHO) constituents were also measured. The kale fed contained $11.4 \mathrm{~g} \mathrm{SMCO} / \mathrm{kg}$ dry matter and the ratio, readily-fermentable: structural $\mathrm{CHO}$ was high at $2 \cdot 9$.

2. Severe haemolytic anaemia, associated with low live-weight gain (LWG), occurred in the lambs during the initial 5 weeks of grazing, due to rumen fermentation of SMCO. Oral methionine supplementation raised plasma concentrations of methionine and cysteine, increased wool growth rate, and increased LWG during the initial 5 weeks. Methionine supplementation also increased rumen pool and plasma SMCO concentrations, suggesting reduced rumen SMCO fermentation.

3. In Expt 2, rumen degradation rate of SMCO $(1 \cdot 2 / \mathrm{h})$ was calculated to be twice as fast as that of the most rapidly fermented dietary CHO constituents and eight times faster than the rate of water outflow $(0 \cdot 16 / \mathrm{h})$, thus explaining its virtually complete rumen degradation and toxicity in brassica diets. It was estimated that 1.2 $\mathrm{g}$ of each $4.0 \mathrm{~g}$ methionine administered would have escaped rumen degradation, due to the high rate of water outflow from the rumen.

4. Disappearance rates of $\mathrm{CHO}$ constituents from the rumen were as predicted for normal ruminant diets, showing that rumen metabolism of SMCO did not have a depressive effect. Hemicellulose disappeared at a slower rate than the other $\mathrm{CHO}$, suggesting that hemicellulose digestion may be rate-limiting for cell-wall digestion.

5. It is suggested that the responses to oral methionine supplementation can be explained through methionine reducing rumen SMCO degradation, and through a significant portion of the methionine escaping rumen degradation.

Nutritional problems causing poor growth in young sheep grazing forage kale (Brassica oleracea) high in metabolizable energy (ME) $(12.5 \mathrm{MJ} / \mathrm{kg}$ dry matter (DM)) and total nitrogen $(25-35 \mathrm{~g} / \mathrm{kg} \mathrm{DM})$ concentration have been investigated, and the prime factor identified as the content of S-methyl-L-cysteine sulphoxide (SMCO), a free amino acid closely related in structure to methionine that occurs in all brassica plants (Barry et al. 1982, $1984 b$ ). SMCO is fermented by rumen bacteria to dimethyl disulphide, which causes haemolytic anaemia, depressed voluntary intake and consequently depressed animal growth.

Quantitative digestion studies (Barry et al. 1984a) showed low amino acid absorption $(14 \%$ of $\mathrm{ME})$ in sheep fed on forage kale whilst, in grazing studies with lambs $(27 \mathrm{~kg})$ both oral or intraperitoneal supplementation with methionine produced similar responses in body growth (Barry \& Drew, 1978), suggesting amino acid deficiency to be a further limiting factor. The objective of the present experiments was to repeat the oral supplementation with methionine, to see if the result could be confirmed and, if so, whether it could be partially explained through competitive enzyme inhibition between methionine and SMCO. A further objective was to measure rumen turnover with a second group of sheep, first to see

\footnotetext{
* Present address: Department of Animal Science, Massey University, Palmerston North, New Zealand.
} 
if responses to oral supplementation with amino acids could be partially explained by an increased rate of rumen water outflow (fractional outflow rate; FOR), and second to obtain a measure of the rate of disappearance of SMCO from the rumen relative to that of carbohydrate $(\mathrm{CHO})$ constituents and to the rate of water outflow.

\section{EXPERIMENT AL}

\section{Animals and diet}

Two experiments were conducted using Romney wether sheep fed on forage kale (Brassica oleracea); the variety N.Z. Medium Stemmed was used in Expt 1 and Maris Kestrel in Expt 2. The kale was used in Expts 1 and 2 about 8-10 months after sowing and was therefore mature, yielding approximately 14 tonnes DM/ha, with a high SMCO content.

\section{Expt 1}

Romney lambs aged 9 months and with a mean initial weight of $27.5 \mathrm{~kg}$ were transferred from grazing ryegrass (Lolium perenne) - clover (Trifolium repens) to grazing kale for a 10 -week period. On Monday and Thursday of each week, twenty-four lambs were given orally $20 \mathrm{ml}$ of a suspension containing $200 \mathrm{~g}$ DL-methionine/l, with colloidal silica and Tween 80 added as the suspending agents (Barry \& Drew, 1978). The remaining twenty-four animals were given orally an equal volume of a control solution comprising the suspending agents.

Twenty animals from each group were weighed after a $24 \mathrm{~h}$ fast at the beginning, mid-point and end of the experiment. Mid-side wool patches of $122.5 \times 122.5 \mathrm{~mm}$ were clipped on the left side at the start of the experiment and wool harvested at the end of weeks 5 and 10. Blood samples were taken from the jugular vein for haematology determinations at 2-week intervals from twelve animals per group. During week 2, plasma samples were taken from four animals per treatment group at $0,6,24$ and $48 \mathrm{~h}$ after oral administration of the control and methionine suspensions, deproteinized immediately and stored at $-20^{\circ}$ until analysed for sulphur-containing amino acids. To ease problems of amino acid analysis, samples were pooled within treatments at each sampling time, giving eight samples overall.

Both treatments groups grazed together and were allowed liberal access to kale, with the feeding break changed every 2.5 weeks. Sufficient area was offered such that leaves and stem tips only were consumed. Cages measuring $2.0 \times 1.0 \mathrm{~m}$ were put on each break at the commencement of grazing and, when the grazing of each break was terminated, samples of kale were taken corresponding to that utilized by the lambs. These were stored at $-20^{\circ}$ and freeze-dried.

During week 4, the four remaining animals in each group were drenched with either the control or methionine-containing suspensions at 16.00 hours and then slaughtered at 09.00 hours the following morning. Total rumen contents were then removed, weighed, samples taken for $\mathrm{DM}$ determination and $\mathrm{pH}$, and a liquid fraction, to be analysed for S-containing amino acids, was prepared by squeezing through two layers of muslin to exclude large particles of undigested feed matter, deproteinized and stored at $-20^{\circ}$.

\section{Expt 2}

Four Romney wether sheep ( $54.7 \mathrm{~kg}$ ) with rumen cannulas were fed on fresh kale at hourly intervals $(650 \mathrm{~g} \mathrm{DM} / \mathrm{d})$ for 3 weeks. The complexes of CrEDTA and of ruthenium Tris(1, 10 phenanthroline)-Ru (II) chloride ( $\mathrm{Ru}$-phen) were prepared as described respectively by Binnerts et al. (1968) and Tan et al. (1971). The two markers were mixed, and the $\mathrm{pH}$ adjusted to 6.5 . Marker solution was infused at $280 \mathrm{ml} / \mathrm{d}$, to supply $10 \cdot 1 \mathrm{mg} \mathrm{Ru} / \mathrm{d}$ and $337 \mathrm{mg} \mathrm{Cr} / \mathrm{d}$ during the last $5 \mathrm{~d}$ of kale feeding. Individual animals were then anaesthetized with sodium pentabarbitone (May \& Baker, UK), the jugular vein and carotid artery cut 
and drained, and the rumen ligated and removed $0,3 \cdot 5,6 \cdot 5$ and $12 \cdot 0 \mathrm{~h}$ after the termination of the infusion (one animal per sampling time). Total rumen contents were weighed and samples taken for DM, Ru and $\mathrm{Cr}$, and $\mathrm{CHO}$ analysis.

\section{Laboratory methods}

Analyses for $\mathrm{CHO}, \mathrm{N}, \mathrm{SMCO}, \mathrm{S}, \mathrm{Ru}$ and $\mathrm{Cr}$ were carried out as described previously (Barry \& Manley, 1984). S-containing amino acids in blood plasma and rumen fluid were determined as described by Barry et al. (1982).

\section{Calculations and statistical analyses}

FOR is defined as the proportion of the total rumen content (i.e. pool) that leaves the rumen per unit time. FOR of CrEDTA and Ru-phen were calculated from the rate of decline in total quantity of $\mathrm{Cr}$ and $\mathrm{Ru}$ present in the rumen following the termination of infusion, using eqn (4) of Faichney (1975). Mean retention time (MRT) was calculated as the reciprocal of FOR. Regressions were calculated of $\ln ($ total $\mathrm{Ru}$ ) or $\ln$ (total $\mathrm{Cr}$ ) present in the rumen $(\mathrm{mg}) v$. time after the infusion ceased, using the points for all four animals.

For $\mathrm{CHO}$ constituents, the definition of rumen turnover terms used are:

$$
\begin{aligned}
& \text { fractional disappearance rate }(F D P R)=\frac{\text { intake }(g / h)}{\text { rumen pool size }(g)}, \\
& \text { fractional degradation rate }(F D R)=\frac{\text { intake }(g / h)-\text { duodenal flow }(\mathrm{g} / \mathrm{h})}{\text { rumen pool size }(\mathrm{g})}, \\
& \text { FOR }=\frac{\text { duodenal flow }(\mathrm{g} / \mathrm{h})}{\text { rumen pool size }(\mathrm{g})} .
\end{aligned}
$$

For substances where there is no net synthesis in the rumen and no input into the rumen other than by diet, then

$$
\text { FDPR }=\text { FDR }+F O R
$$

FDPR was measured directly in Expt 2 (eqn (1)). FOR for SMCO was assumed to be the same as measured for water using CrEDTA, whilst FOR for CHO constituents (proportion/h) was taken from Barry et al. (1984a; water soluble CHO 0.057, pectin 0.017, hemicellulose $0 \cdot 021$, cellulose $0 \cdot 027$ ).

Results collected in Expt 1 were statistically analysed using analysis of variance.

\section{RESULTS}

\section{Chemical composition of diet}

The kale contained high concentrations of readily-fermentable $\mathrm{CHO}$ (water-soluble $\mathrm{CHO}$ and pectin) and low concentrations of structural $\mathrm{CHO}$ (hemicellulose and cellulose) and lignin (Table 1). The kale also contained a substantial proportion of the total $\mathrm{N}$ as non-protein- $\mathrm{N}$, and high concentrations of both total $\mathrm{S}$ and SMCO.

\section{Responses to oral supplementation with methionine-containing suspension}

Concentrations of SMCO in rumen fluid of control sheep (Table 2) were much lower than those for other S-containing amino acids. Oral methionine supplementation increased the size of the rumen water and DM pools, and consistently increased both the concentration and pool size of the four S-containing amino acids measured, although none of the differences attained significance $(P>0.05)$. Of the $4 \mathrm{~g}$ methionine administered into the rumen, some $11 \mathrm{mg}$ remained in solution $17 \mathrm{~h}$ later.

Relative to control sheep, those given the oral methionine-containing suspension showed 
Table 1. Chemical composition $(\mathrm{g} / \mathrm{kg}$ dry matter) of diets fed

\begin{tabular}{lcc}
\hline & Expt 2 & Expt 1 \\
\hline Soluble CHO & 241 & 300 \\
Pectin & 108 & ND \\
Hemicellulose & 46 & ND \\
Cellulose & 73 & ND \\
Lignin & 59 & ND \\
Readily-fermentable CHO: structural CHO & 2.93 & ND \\
Total nitrogen & 33.3 & 18.6 \\
Protein-N (proportion of total N) & 0.85 & 0.52 \\
Total sulphur & 8.5 & 6.0 \\
SMCO & 11.8 & 11.0 \\
\hline
\end{tabular}

ND, not determined; CHO, carbohydrate; SMCO, S-methyl-L-cysteine sulphoxide.

Table 2. Expt 1. Concentration ( $\mu \mathrm{mol} / \mathrm{l})$ and pool sizes ( $\mathrm{mg}$ ) of free sulphur-containing amino acids in the rumen fluid of kale (Brassica oleracea)-fed sheep

(Mean values with their standard errors of the difference (SED) for four animals per group. Values were determined at slaughter $17 \mathrm{~h}$ after oral administration of control or methionine-containing suspensions)

\begin{tabular}{|c|c|c|c|}
\hline & Control & Methionine-supplemented & SED \\
\hline \multicolumn{4}{|c|}{ Concentration } \\
\hline Methionine & $24 \cdot 0$ & 56.9 & 20.06 \\
\hline Cystine & $48 \cdot 6$ & $72 \cdot 0$ & 25.84 \\
\hline SMCO & $7 \cdot 3$ & $16 \cdot 6$ & $12 \cdot 20$ \\
\hline Cysteic acid & $48 \cdot 6$ & $72 \cdot 0$ & 25.84 \\
\hline \multicolumn{4}{|c|}{ Pool size } \\
\hline Dry matter (g) & $148 \cdot 9$ & $210 \cdot 0$ & $29 \cdot 91$ \\
\hline Water (l) & 1.55 & 1.89 & $0 \cdot 181$ \\
\hline Methionine & $5 \cdot 6$ & 16.8 & $6 \cdot 11$ \\
\hline Cystine & $9 \cdot 5$ & $16 \cdot 9$ & 6.52 \\
\hline SMCO & 1.7 & $5 \cdot 4$ & 3.87 \\
\hline Cysteic acid & $18 \cdot 8$ & $32 \cdot 6$ & $7 \cdot 10$ \\
\hline
\end{tabular}

SMCO, S-methyl-L-cysteine sulphoxide.

increased plasma concentrations of methionine in samples taken $6 \mathrm{~h}$ after administration, increased SMCO concentration in samples taken 6 and $24 \mathrm{~h}$ after administration and increased cystine concentrations in samples taken 24 and $48 \mathrm{~h}$ after administration (Fig. 1). Severe haemolytic anaemia developed in both groups during the initial 4 weeks of grazing on kale, which reduced markedly in severity between weeks 6 and 10, and which tended to be slightly, but not significantly, less severe in the lambs drenched with methionine (Fig. 2).

Rates of live-weight gain (LWG) (Table 3) were low during the first 5 weeks, corresponding to the period of severe anaemia, and were increased approximately $45 \mathrm{~g} / \mathrm{d}$ by oral methionine supplementation over this period $(P<0.05)$. Thereafter, rates of body growth increased to $145 \mathrm{~g} / \mathrm{d}$ and were unaffected by methionine supplementation. Wool growth was increased by methionine supplementation, with the response attaining significance during weeks $6-10(P<0.05)$. 

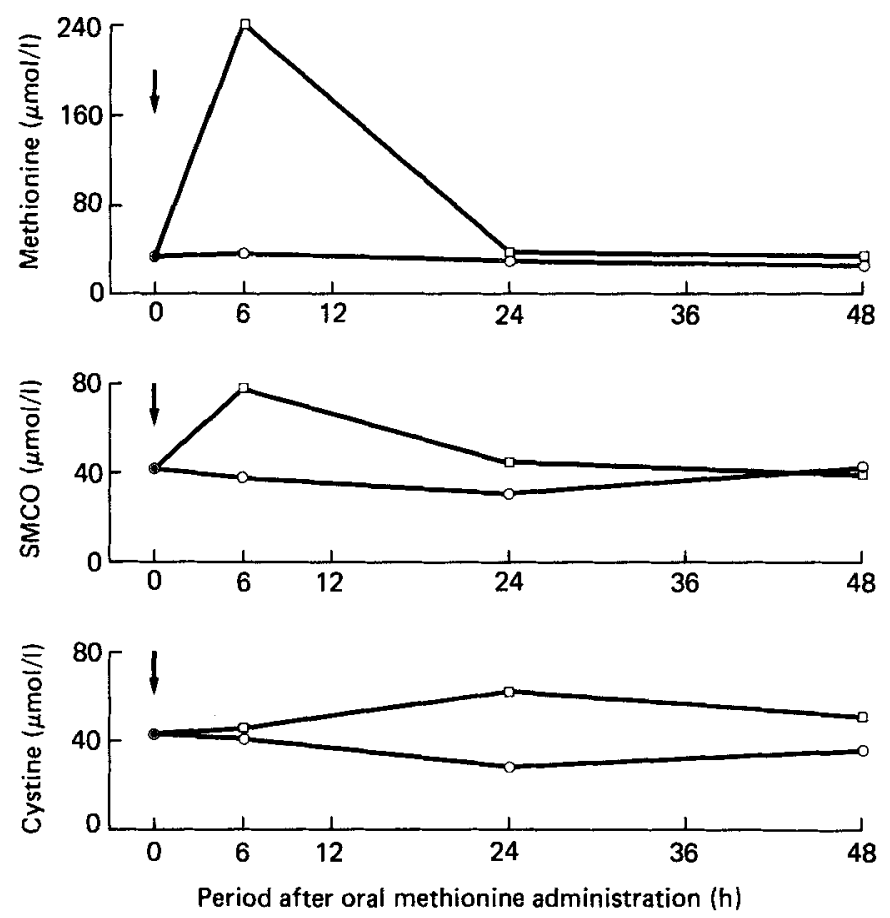

Fig. 1. Expt 1. Changes in plasma concentrations of methionine, S-methyl-L-cysteine sulphoxide (SMCO) and cystine following oral methionine adminstration to lambs grazing kale (Brassica oleracea) of high SMCO content. (O), Control lambs: $(\square)$, methionine-supplemented lambs; $(\downarrow)$, time of methionine administration.

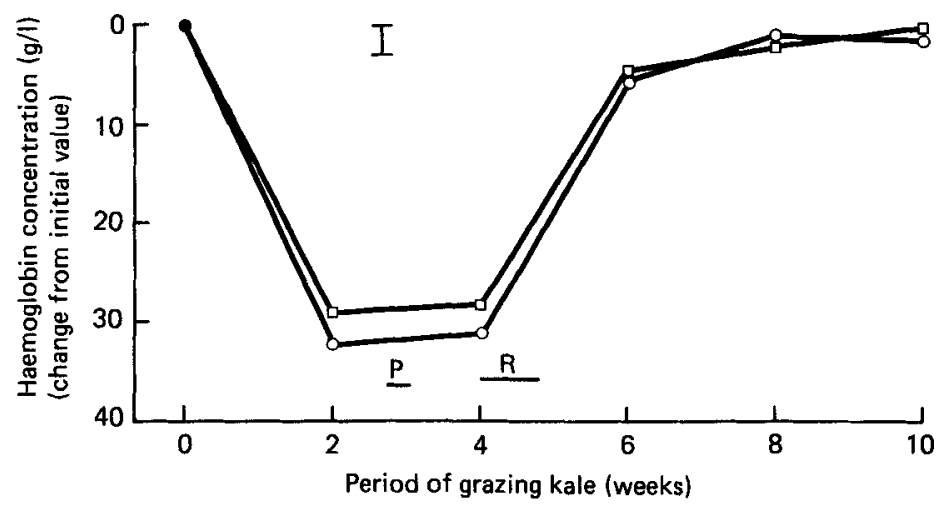

Fig. 2. Expt 1. Changes in whole blood haemoglobin concentration in lambs grazing kale (Brassica oleracea) of high S-methyl-L-cysteine sulphoxide (SMCO) content. Mean initial concentation was $117 \cdot 2$ $\mathrm{g} / \mathrm{l}$. (P), Period over which plasma taken for sulphur-containing amino acid analyses; $(\mathbf{R})$, period over which sheep slaughtered to determine concentration and pool size of S-containing amino acids in rumen fluid. $(O)$, Control lambs; $(\square)$ methionine-supplemented lambs. Vertical bar represents standard error of mean averaged over all sampling times. 
Table 3. Expt 1. Live-weight gain $(\mathrm{g} / \mathrm{d})$ and wool growth $\left(\mathrm{mg} / 10^{4} \mathrm{~mm}^{2}\right.$ per d) in lambs grazing kale (Brassica oleracea)

(Mean values with their standard errors of the difference (SED) for twenty animals per group)

\begin{tabular}{|c|c|c|c|}
\hline $\begin{array}{l}\text { Period of experiment } \\
\text { (weeks) }\end{array}$ & Control & Methionine-supplemented & SED \\
\hline \multicolumn{4}{|c|}{ Live-wt gain } \\
\hline $1-5$ & $-6 \cdot 3$ & 37.1 & 14.7 \\
\hline $6-10$ & 147 & 140 & $16 \cdot 1$ \\
\hline $1-10$ & 70 & 89 & $9 \cdot 5$ \\
\hline \multicolumn{4}{|c|}{ Wool growth } \\
\hline $1-5$ & $45 \cdot 3$ & $48 \cdot 4$ & $2 \cdot 90$ \\
\hline $6-10$ & $65 \cdot 4$ & $81 \cdot 5$ & 6.73 \\
\hline $1-10$ & $54 \cdot 3$ & $65 \cdot 0$ & 4.48 \\
\hline
\end{tabular}

\section{Rumen turnover}

In total $\mathrm{Cr}$ and $\ln$ total $\mathrm{Ru}$ present in the rumen were related to time $(\mathrm{T} ; \mathrm{h})$ following the cessation of the infusion by the relations:

$$
\begin{aligned}
& \mathrm{Cr}=4.47(\mathrm{SE} 0.172)-0.155(\mathrm{SE} 0.0244) \mathrm{T}, \quad r 0.976 \\
& \mathrm{Ru}=1.48(\mathrm{SE} \mathrm{0.33)}-0.048(\mathrm{SE} 0.0046) \mathrm{T}, \quad r 0.991 .
\end{aligned}
$$

Rumen FOR for CrETDA and Ru-phen were thus $0 \cdot 16 / \mathrm{h}$ and $0 \cdot 05 / \mathrm{h}$ respectively, giving mean retention times in the rumen of 6.5 and $20.8 \mathrm{~h}$ respectively.

Rumen FDPR was in the order SMCO > water-soluble CHO and pectin $>$ cellulose $>$ hemicellulose (Table 4), with the value for SMCO being double the rate of disappearance of the fastest-fermented CHO. Rumen outflow of SMCO was calculated to be zero, whilst the extent of $\mathrm{CHO}$ degradation in the rumen was as predicted for normal grass and legume diets.

\section{DISCUSSION}

\section{Rumen degradation and outflow of methionine}

The quantity of methionine administered that was washed out of the rumen undegraded can be estimated from a knowledge of rumen water volume and its FOR, together with an estimate of methionine degradation rate by rumen organisms.

Using a rumen water volume of $2 \cdot 1$ litres with an outflow rate of $0 \cdot 16$ litres $/ \mathrm{h}$ as measured for kale-fed sheep, and the degradation rate for methionine determined by Chalupa (1976) with mixed rumen organisms $(2 \cdot 1 \mathrm{~g} / \mathrm{h}$ for $2 \cdot 1$ litres $)$, it can be calculated that the $4.0 \mathrm{~g}$ methionine per sheep given in Expt 1 would have declined virtually to zero in the rumen by $1.5 \mathrm{~h}$, with $2.85 \mathrm{~g}$ being degraded and $1.15 \mathrm{~g}$ being washed into the abomasum with the rumen water outflow. This is supported by the sixfold increase in plasma methionine concentration in samples taken $6 \mathrm{~h}$ after its administration. As plasma cystine concentration was increased for up to $48 \mathrm{~h}$ after methionine supplementation, it seems that the treatment increased the amount of cystine available to the animal over a longer time-span, and this is supported by the increase in wool growth, a process limited by cystine supply (Reis, 1979). The rather slow response in measured wool growth (Table 3) can be explained by the time required for wool synthesized in the follicle to pass through the skin and reach a height where it can be cut. 


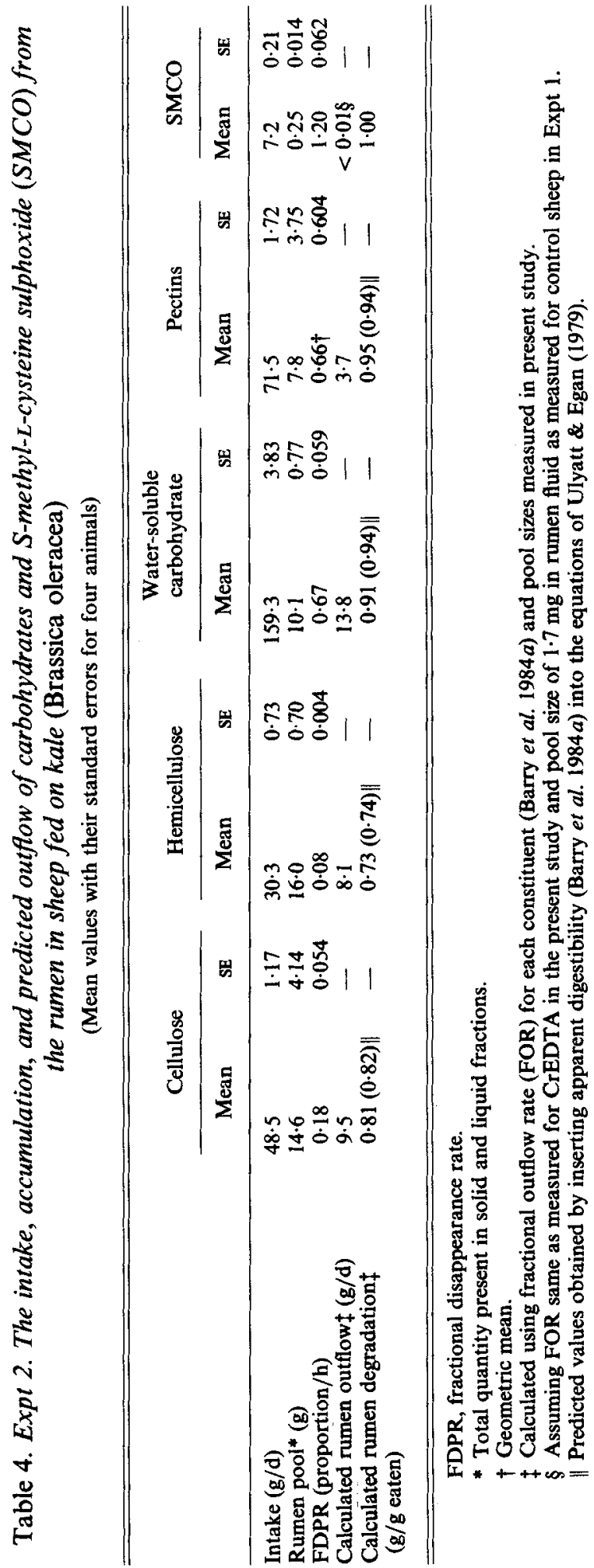




\section{Rumen degradation and outflow of $S M C O$ and of $\mathrm{CHO}$}

SMCO is fermented by mixed rumen organisms to dimethyl disulphide (Smith, 1974). The zero rumen outflow, confirmed by direct duodenal measurement (Barry et al. 1984a), gives an FOR of zero and FDR equal to the FDPR of $1.20 / \mathrm{h}$ (eqn (4)). The extreme toxicity of SMCO in kale diets is therefore explained by its very rapid rate of degradation in the rumen per unit time, which is 7.7 times faster than its rate of outflow (water FOR) and approximately twice the FDR found by Barry et al. (1984a) for water-soluble CHO and pectins $(0 \cdot 6 / \mathrm{h})$, the most rapidly fermented $\mathrm{CHO}$ components in sheep fed on kale diets.

Oral methionine supplementation probably reduced this high rumen SMCO degradation in Expt 1, as judged by the increased rumen SMCO pool, the rise in plasma SMCO concentration following methionine administration, and the less-severe anaemia and increased LWG of methionine-drenched sheep during weeks 1-5. Absorbed SMCO is metabolized to carbon dioxide by the formate pathway in mammals (Case \& Benevenga, 1977 ) and is unlikely to depress animal growth. Very low rates of LWG during the first 5 weeks, coinciding with the period of severe haemolytic anaemia, is a characteristic of feeding all brassica diets (Nicol \& Barry, 1980), and was exceptionally severe in Expt ${ }^{-1}$ presumably due to the high SMCO content of the kale fed. The greater rumen DM and water pools in sheep receiving oral methionine suggest that this treatment may have increased LWG through stimulating voluntary DM intake.

As the proportion of each carbohydrate digested in the rumen was almost exactly as predicted by Ulyatt \& Egan (1979) for normal ruminant diets, it seems that dimethyl disulphide production in the rumen did not reduce the activity of CHO-digesting enzyme systems in the rumen. Also, with this brassica diet where the apparent digestibility of structural carbohydrate exceeds $90 \%$, it seems that hemicellulose digestion is rate-limiting for cell-wall digestion in the rumen, probably due to bonding with lignin.

In conclusion, the present study has confirmed that an oral supplement of methionine increases both LWG during the severe haemolytic phase and wool growth in young sheep grazing Brassica oleracea containing high concentrations of SMCO. It is suggested that the responses can be explained through methionine reducing rumen degradation of SMCO, and by a significant portion of the methionine being washed undegraded into the abomasum due to the high FOR of water from the rumen.

The authors acknolwedge technical assistance by Mr S. J. Duncan, Mrs R. W. Harrex, Mr A. W. Williams, Mr B. A. Vennvliet and Mrs J. Crosbie. Professor G. Peterson, Department of Biochemistry, Otago University is thanked for permitting the use of the Department's amino acid analyser.

\section{REFERENCES}

Barry, T. N \& Drew, K. R. (1978). New Zealand Journal of Agricultural Research 21, 395-399.

Barry, T. N. \& Manley, T. R. (1984). British Journal of Nutrition 51, 493-504.

Barry, T. N., Manley, T. R \& Duncan, S. J. (1984a). Journal of Agricultural Science, Cambridge 102, $479-486$.

Barry, T. N., Manley, T. R. \& Millar, K. R. (1982). Journal of Agricultural Science, Cambridge 99, 1-12.

Barry, T. N., Manley, T. R., Millar, K. R \& Smith, R. H. (1984b). Journal of Agricultural Science, Cambridge 102, 635-643.

Binnerts, W. T., Van 't Klooster, A. T. \& Frens, A. M. (1968). Veterinary Record 82, 470.

Case, G. L. \& Benevenga, N. T. (1977). Joumal of Nutrition 107, 1665-1676.

Chalupa, W. (1976). Journal of Animal Science 43, 828-834.

Faichney, G. J. (1975). In Digestion and Metabolism in the Ruminant. Proceedings IV International Symposium on Ruminant Physiology, pp. 277-291 [I. W. McDonald and A. C. I. Warner, editors]. Armidale, Australia: New England Publishing Unit.

Nicol, A. M. \& Barry, T. N. (1980). In Supplementary Feeding. NZ Society of Animal Production Occasional Publication no. 7, pp. 69-102 [K. R. Drew and P. F. Fennessy, editors]. Mosgiel, New Zealand: Invermay Research Centre. 
Reis, P. J. (1979). In Physiological and Environmental Limitations to Wool Growth, pp. 223-242. [J. L. Black and P. J. Reis, editors]. Armidale, Australia: New England Publishing Unit.

Smith, R. H. (1974). Report of the Rowett Institute 30, 112-131.

Tan, T. N., Weston, R. H. \& Hogan, J. P. (1971). International Journal of Applied Radiation and Isotopes 22, 301-308.

Ulyatt, M. J. \& Egan, A. R. (1979). Journal of Agricultural Science, Cambridge 92, 605-616. 